\title{
Management of Spontaneous Rectal Perforation at Up-Coming Medical College Hospital: A Rare Occurrence
}

\author{
Singh $R K^{\prime}$
}

\section{Affiliation:}

1. Professor, Department of Surgery, Birat Medical college \& Teaching Hospital, Tankisinuwari-02, Morang, Nepal

\section{ARTICLE INFO \\ Article History \\ Received : 28 Nov, 2016 \\ Accepted : 15 Dec, 2016 \\ Published : $20 \mathrm{Dec}, 2016$ \\ (C) Authors retain copyright and grant the journal right of first publication with the work simultaneously licensed under Creative Commons Attribution License CC - BY 4.0 that allows others to share the work with an acknowledgement of the work's authorship and initial publication in this journal.}

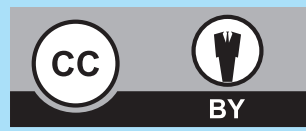

* Corresponding Author

Dr. R. K. Singh

Professor

Department of Surgery

Birat Medical College \& Teaching Hospital

Tankisinuwari-02, Morang, Nepal

Email: ramkumarsingh2034@gmail.com

\section{Citation}

Singh R. K. Management of Spontaneous Rectal Perforation at Up-Coming Medical College Hospital: A Rare Occurrence BJHS 2016; 1 (1) 1:87-90.

\section{ABSTRACT}

Spontaneous perforation of large bowel compare to small bowel is very uncommon and among them "spontaneous rectal perforation" is very rare cause of acute abdomen in surgical practice. The presentation of such entity is similar to any other cause of peritonitis \& pre-operatively definite diagnosis remain a diagnostic dilemma and require an emergency surgical intervention to have the best outcome.

We report a case of a 83 years male presented to our Emergency Department referred from B. P. Koirala Institute of Health Sciences with feature suggestive of peritonitis, hollow viscous perforation with evidence of free air under right dome of diaphragm in chest X-ray PA view. An emergency exploratory laparotomy was performed with provisional diagnosis of duodenal ulcer perforation as being commonest in this region with differential diagnosis of appendicular perforation or small bowel perforation with peritonitis. But on exploration no perforation was found in duodenum, small bowel, appendix and large bowel etc. Lastly with much difficulty the rectal perforation could be located while removing the plaques adhered to the rectal wall. Seeing such cases a surgeon should be aware of the possibility of this fatal disease despite rare incidence. It is very important to recognize such condition at an early stage because it carries high mortality if surgical intervention is not done at early stage. Intra-operatively too a thorough search should be made towards rectum if perforation is not found easily at other sites. Hence the better prognosis is with early surgical intervention; worst the prognosis with late intervention.

\section{KEYWORDS}

Peritonitis, rectal perforation, spontaneous 


\section{INTRODUCTION}

Hollow viscous perforation is very common entity in surgical practice leading to acute abdomen. Usually the rectal perforation occurs in cases of pre-existing pathology such as trauma, iatrogenic injury eg. During colonoscopy, however spontaneous rectal perforation is very extremly rare. ${ }^{1}$ There are no specific clinical manifestations of such disease and it usually leads to severe peritonitis in absence of sign and symptoms by the time diagnosis is made. Hence, a surgeon should be aware of such condition and must have high suspicion of index for diagnosing such cases and early surgical exploration is required to have a good outcome and to reduce mortality rate. We report a case of severe peritonitis due to spontaneous rectal perforation which was successfully managed surgically and discharged with functioning status loop colostomy on $8^{\text {th }}$ post-operative day. Patient was brought back after 20 days in Emergency with pus discharge from main wound and drain site with status functioning colostomy. Patient was examined and found to have burst abdomen with a cavity on right paracolic gutter so a corrugated drain was kept through right drain site and interrupted suture applied to the main wound. Patient was discharged after two days with advice: daily dressing, high protein high calories diet and care of the colostomy with regular follow up in OPD. On follow up after two months, patient was well tolerating orally and normal functioning colostomy and well wound healed. Patient was advised to report to SOPD for closure of loop colostomy after three months.

Figure 1: CXR showing free air under right dome of diaphragm

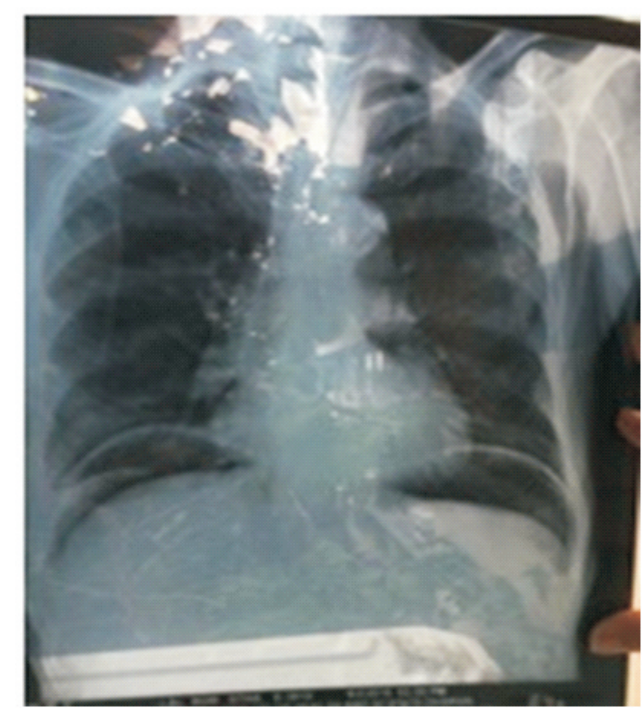

Figure 2: Rectum showing perforation with tip of thumb forceps

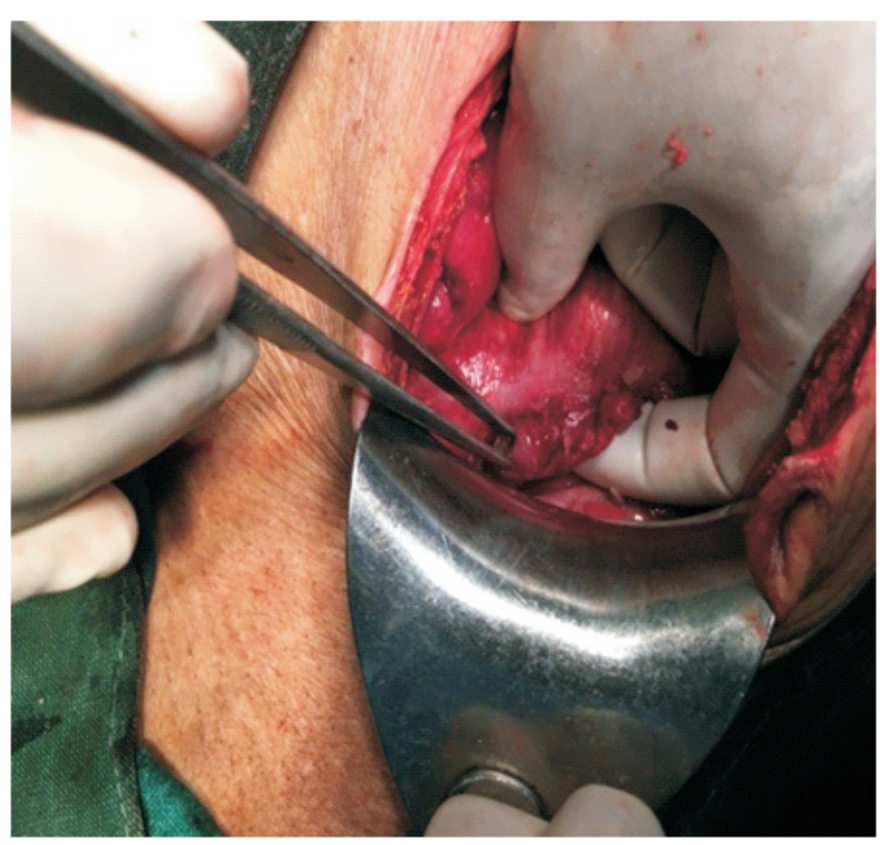

\section{CASE REPORT}

A 83 year old male from Dhankuta was referred to our hospital from BPKIHS, Dharan with provisional diagnosis of hollow viscous perforation with diffuse peritonitis with free air under right dome of diaphragm. Patient was presented with acute onset of pain abdomen followed by generalized pain abdomen for 2 days. Constipation for 2 days \& Obstipation for 1 day. No history of vomiting, fever. He Had gradually increasing distension of abdomen \& passage of less urine. There was no history of habitual constipation and consumption of laxatives, abdominal surgery, rectal prolapse or abdominal trauma. There is no familyhistory of similar illness or gastrointestinal cancers.

On examination, the general was poor, dehydrated, sunken eyes and pulse rate was 107 beats/ minute, blood pressure was $140 / 90 \mathrm{mmHg}$, respiratory rate $24 /$ minute, temperature $98 \mathrm{~F}$, SPo2 without oxygen $88 \%$ and with oxygen $96 \%$. The examination of abdomen revealed hard rigid mass with rebound tenderness and masked liver dullness. Bowel sounds were absent. Per rectal examination revealed no mass and no possible causes for constipation in the pre-operative period. White blood cell count was slightly raised with Neutrophil 97\%, lymphocyte $07 \%$ \& eosinophils $01 \%$ (shift to left). Blood urea nitrogen 35 $\mathrm{mg} / \mathrm{dl}$ (6-20), Serum creatinine $1.3 \mathrm{mg} / \mathrm{dl}, \mathrm{Na}+: 150 \mathrm{meq} / \mathrm{Lt}, \mathrm{K}+$ : $3.6 \mathrm{meq} / \mathrm{Lt} \& \mathrm{Cl}$ - : $102 \mathrm{meq} / \mathrm{Lt}$. X-ray Chest showed free gas under right dome of diaphragm. A diagnosis of hollow viscous perforation with peritonitis with pre-renal azotaemia was made and an emergency exploratory laprotomy was performed after 
initial resuscitation. Intra-operatively Guss of air and about $1000 \mathrm{ml}$ of faeco-purulent, foul smelling thick fluid was found spread all over peritoneal cavity mainly in the pelvis. A solitary perforation of approximately $0.5 \mathrm{cms}$ diameter with healthy margins was identified in anterior wall of the rectum about $20 \mathrm{cms}$ from anal verge and about $12 \mathrm{cms}$ proximal to peritoneal reflection. There was no diverticular diseases of the colon, Sigmoid colon was loaded with fecal matter. A simple closure of the perforation followed by a diversion transverse loop colostomy was performed after thorough irrigation of the peritoneal cavity. No biopsy was taken from the perforation site for histopathlogical examination. A tube drain kept in the pelvis. Abdomen closed with vicryl no 1 as mass closure and skin closed with ethilon 2/0 interrupted.

On table maturation of the colostomy was performed and non-adhesive dressing applied. The post-operative period was uneventful. Patient was managed in ICU for two days and then shifted to the general surgical ward and discharged on $8^{\text {th }}$ post-operative day.

Patient was brought back after 20 days in Emergency with pus discharge from main wound and drain site with status normal functioning colostomy. Patient was examined and found to have burst abdomen with a cavity on right para-colic gutter. So a corrugated drain was kept through right drain site and interrupted suture applied to the main wound. Patient was discharged after two days with advice: daily dressing, high protein high calories diet and care of the colostomy with regular follow up in OPD. On follow up after two months, patient was well tolerating orally and normal functioning colostomy and wound was well healed (Figure 3, 4). Patient was advised to report to SOPD for closure of loop colostomy after three months.

Figure 3:

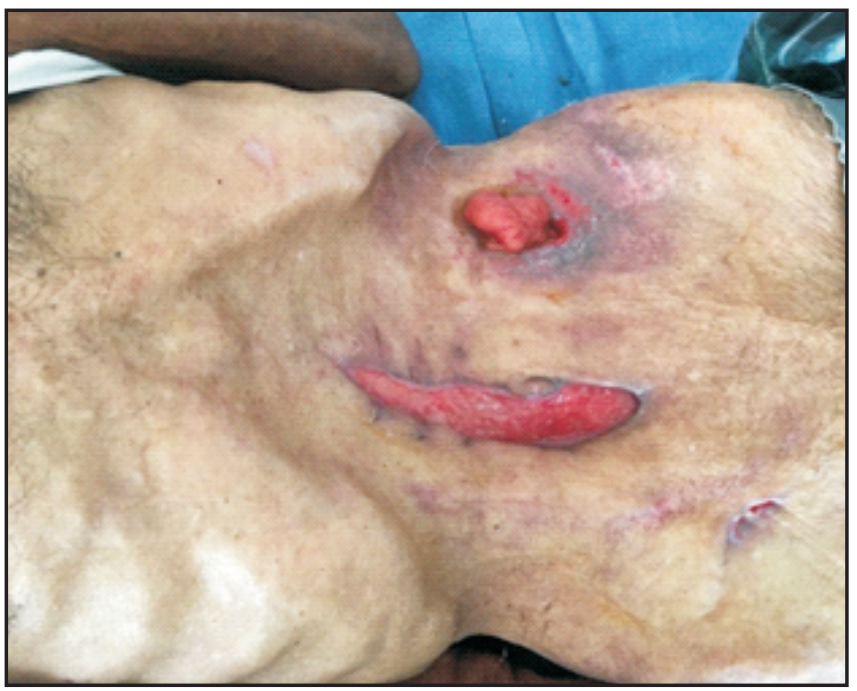

Figure 4:

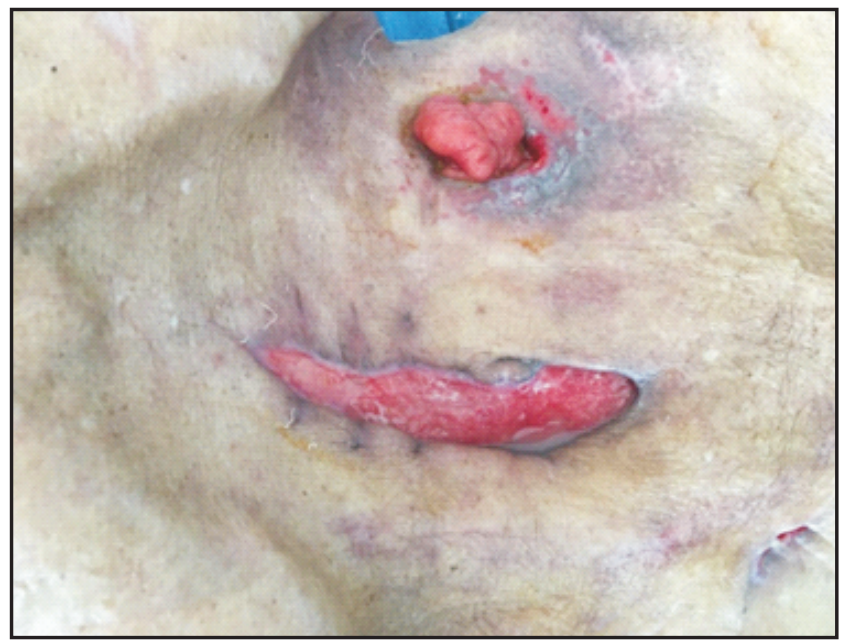

\section{DISCUSSION}

The incidence of spontaneous perforation of sigmoid colon or rectum is very rare. It does occur in all age groups, the youngest reported case being six years old and the oldest ninety six years old. ${ }^{2}$ The perforation is often associated with intra-luminal pressure during defection with a pre-existing pathology such as diverticulitis, colitis, ulceration, malignancy, irradiation, adhesions or as a consequence of iatrogenic injuries and blunt trauma abdomen. ${ }^{1}$ Chronic straining due to pre-existing disease causes progressive deepening of recto-vesical and recto-uterine pouches leading to thinning of rectal wall. Various theories have been postulated in an effort to explain the mechanism of spontaneous rectal perforation. Among them the most prevailing are:

1. Intramural hematoma formation resulting in dissection and weakening of the rectal wall.

2. Congenital anal dysplasia coexisting with a weakened area of rectal wall.

3. Progressive deepening of the pouch of Douglas in combination with sudden increase of intra-abdominal pressure could cause rupture of the rectum. ${ }^{3}$

The perforation occurs almost always in the distal part of the colon because of the physiological characteristics of rectosigmoid colon such as lower water content of the stool, relatively poor blood supply and high pressure due to the narrowed intra-luminal diameter ${ }^{4}$ and it involves the anterior wall of the rectum just proximal to the peritoneal reflection at the anti-mesenteric border of the recto-sigmoid junction. ${ }^{4}$ In most cases, it presents with features of diffuse peritonitis and $X$-ray chest shows free air under right dome of diaphragm. The treatment of this entity requires urgent surgical exploration with closure of the perforation and proximal 
diversion colostomy. The gut continuity may be restored after 3 or 4 months of surgery. ${ }^{5}$ It is important to bear in mind that in patients with severe contamination, septic shock and delayed treatment, the mortality rate is over $60 \%$. ${ }^{6}$

\section{CONCLUSION}

Though spontaneous rectal perforation is very rare, surgeons working at periphery with limited resources should have high suspicious index to diagnose such case to have early diagnosis so that at earliest surgical intervention performed to have best outcome. Rectal perforation is one of the important causes of acute abdomen and should always be kept in mind to suspect when a patient with chronic constipation presents with severe abdominal pain and absence of feature of peritonitis. The mortality rate for this condition is very high, although the incidence is very low and timely intervention can save the life in most cases.

\section{REFERENCES :}

1. Tokunaga $Y$, Hata K, Nishitai R, Kaganoi J, Nanbu H, Ohsumi K. Spontaneous perforation of the rectum with possible stercoral etiology: report of a case and review of the literature. Surg Today 1998;28:937-939.

2. Schein M, Decker GAG. Spontaneous perforation of the rectum. SAMJ 1986;69:388-389.

3. Penopoulous V, Maris T, Gougoulias N, Christianopoulos G, Kokozidis G, Kitis G. Spontaneous extraperitoneal rupture of the rectum. Ann Gastroenterol 2002;15:186-189.

4. Demirag A, Nurlu H, Gurer A, Turkyilmaz Z,Oguz M. Spontaneous perforation of rectum and rectosigmoid junction. Case report. Mater Med Pol 1993;15:47-48.

5. Zhang J, Jian-bin WU. Diagnosis and treatment of spontaneous colonic perforation: report of 9 cases. China General Surgery 2005,10:769-771.

6. Hikita H,Kaneko G, Horigome N, Senga O, Wada Y. Spontaneous perforation of the rectosigmoid colon: a report of 2 cases. Chin Med J 2001:114:431-432.
10. Kawauchi S, Tsujı T, Kaku T, Kamura T, Nakano H, Tsuneyoshi M. Sclerosing stromal tumor of the ovary: a clinicopathologic, immunohistochemical, ultrastructual and cytogenetic analysis with special reference to its vasculature. Am J Surg Pathol. 1998;22:83-92

11. Cashell AW, Cohen ML. Masculinizing slerosing stromal tumor of the ovary during pregnancy. Gynecol Oncol. 1991;43:281-85. 8. Liang YF, Zeng JC, Ruan JB, Kang DP,

12. Ozdemir O, Sari ME, Sen E, Kurt A, Ileri AB, Atalay CR. Sclerosing stromal tumour of the ovary: A case report and the review of literature. Niger Med J 2014;55:432-7

13. Baker PM, Oliva E. Immunohistochemistry as a tool in the differantial diagnosis of ovarian tumors: an update. Int J Gynecol Pathol. 2004;24:39-55.

14. McCluggage WG, Maxwell P. Immunohistochemical staining for calretinin is useful in the diagnosis of ovarian sex-cord stromal tumours. Histopathology. 2001;38: 403-08.

15. Zhao C, Vinh NT, Mc Manus K, Dabbs D, Barner R, Vang R. Identification of the most sensitive and robust immunohistochemical markers in different categories of ovarian sex cord-stromal tumors. Am J Surg Pathol. 2009;33:354-66. 